\title{
Estimating crop model parameters for simulating soybean production in Iran conditions
}

\author{
Alireza Nehbandani ${ }^{1}$, Afshin Soltani ${ }^{1}$, Faranak Nourbakhsh ${ }^{2}$ and Amir Dadrasi ${ }^{3, *}$ \\ ${ }^{1}$ Department of Plant Production, Gorgan University of Agricultural Sciences, Gorgan, Iran \\ 2 SWEP Analytical Laboratories, Melbourne, Australia \\ ${ }^{3}$ Department of Agronomy, Agriculture College, Vali-e-Asr University of Rafsanjan, Kerman, Iran
}

Received 24 March 2020 - Accepted 2 October 2020

\begin{abstract}
Crop modelling has the potential to contribute to food security. In this study, to provide a simple model for estimating the soybean potential yield and phenological stages in Iran, a simulation model (SSM_iCrop2) was parameterized and tested. This model estimates the soybean phenological stages and potential yield based on the weather data (minimum and maximum temperature, solar radiation and rainfall) using the phenological models such as leaf area development, mass production and partitioning and soil water balance. Regarding the model parametrization, the two maturities groups of 3 and 5 with the temperature unit of 2000 and 2400 growth degrees day (GDD) were chosen. The model evaluation results indicated that the soybean yield ranged between 1.9 and 4.8 with the average of $3.5 \mathrm{t}^{-h a^{-1}}$, while the range of simulated yield changes between 1.8 and 4.7 with the average of $3.7 \mathrm{tha}^{-1}$. Comparing the observed yield to the simulated yield, values of $\mathrm{r}, \mathrm{CV}$ and RMSE were obtained $0.84,13 \%, 0.5 \mathrm{t}^{-h \mathrm{a}^{-1}}$ which indicates the high accuracy of the model. All of these results indicated that the estimated model parameters are high accuracy for use in the simulation of soybean yield at the country level.
\end{abstract}

Keywords: parameterization / evaluation / food security / crop model / climate change

Résumé - Estimation des paramètres d'un modèle de culture simulant la production de soja en Iran. La modélisation des cultures peut contribuer à la sécurité alimentaire. Dans cette étude, un modèle de simulation (SSM_iCrop2) a été paramétré et testé afin d'estimer les stades phénologiques et le rendement potentiel du soja en Iran. Ce modèle simple s'appuie sur une base de données météorologiques (température minimale et maximale, rayonnement solaire et précipitations) pour estimer la phénologie, la surface foliaire, la production et l'allocation de la biomasse, et le bilan hydrique du sol. Pour le paramétrage du modèle, seuls les groupes de maturité III et V correspondant à des sommes de température de 2000 et 2400 degrés-jours ont été retenus. Les résultats de l'évaluation du modèle ont indiqué que le rendement observé du soja se situait entre 1,9 et 4,8 t.ha ${ }^{-1}$, avec une moyenne de 3,5 t.ha ${ }^{-1}$, tandis que la gamme des rendements simulés variait de 1,8 à 4,7 t.ha $^{-1}$ avec une moyenne de 3,7 th.ha ${ }^{-1}$. En comparant le rendement observé au rendement simulé, on a obtenu des valeurs de r, CV et RMSE de $0,84,13 \%, 0,5 \mathrm{t}^{-\mathrm{ha}^{-1}}$,respectivement, ce qui souligne la grande précision du modèle. Tous ces résultats indiquent que les paramètres estimés pour ce modèle sont suffisamment précis pour être utilisés dans la simulation du rendement du soja au niveau national.

Mots clés : paramétrage / évaluation / sécurité alimentaire / modèle de culture / changement climatique

\section{Introduction}

Soybean (Glycine max) is one of the most important oilseed crops cultivated in the world. Soybean crop area and

\footnotetext{
H7 Contribution to the Topical Issue "Soybean / Soja".

*Correspondence: V.dadrasi@gmail.com
}

production in Iran are about 66000 hectares and 151000 tons, respectively which does not meet the domestic needs, so imported soybean meal to Iran amounted to 2.37 million tonnes with the worth of $\$ 1.5$ billion in 2012 (Ministry of Agriculture Jihad, 2016). Also, imported soybean oil was about 800000 tonnes worth $\$ 960$ million in 2013 (FAOSTAT, 2013). So far, several attempts have been made using field experiments to better understand factors affecting crop yield 
per unit area. Field experiments on the crop response to various environmental conditions are laborious and costly. Due to these constraints, crop models can be useful tools to study and estimate the yield (Geerts and Raes, 2009) A mathematical model is an equation or set of equations that describes the behaviour of each system quantitatively (Soltani, 2009). To predict the crop growth, studies on phenology, mass production and partitioning, leaf area development and soil water balance are required (Dadrasi and Torabi, 2016). Precise prediction of the crop phenology is one of the essential features of the simulation models. The mass production and partitioning are largely regulated by the timing of developmental stages in crop simulation models (Soltani, 2012). Simple models can be more efficient in yield analysis and investigate the limiting factors due to easy manufacturing, testing, applying, understanding and interpretation of results; In addition it needs minimum inputs (Sinclair and Muchow, 1999). One of the other benefits of modelling is the prediction of the food production status in one area and making decisions based on environmental changes. Models apply a variety of plant and environmental parameters to simulate crop growth and they should be calibrated and evaluated before being used (Hsiao et al., 2009). In some models, the parameters related to plant characteristics may have been calculated according to the climate of a certain region, which is not usable in other regions or may not have acceptable performance. Therefore, to predict the crop growth and yield by the model, the compatibility of the equations with the relationships between the different processes of growth and yield and the climatic conditions of the study area, access to the input parameters and the model efficiency in predicting growth and yield should be considered (Torabi et al., 2011).

Some used models for simulation of soybean yield and phenological stages include EPIC (Williams and Watson, 1985), SoySim (Setiyono et al., 2010), CROPGRO-Soybean (Boote et al., 1998) and APSIM (Keating et al., 2003). There is another a group of plant models, called SSM_iCrop2 (Soltani et al., 2020a). SSM iCrop2 model simulated a large number of plant species including orchard species and perennial forages (Soltani et al., 2020a).

Therefore, the aim of this study was to determine the SSM_iCrop2 parameters in simulating main cultivars soybean growth and yield in Iran to provide a tool for analysing yieldlimiting factors, optimizing field management and identifying the factors that influence the yield increase in certain environmental conditions.

\section{Material and methods}

\subsection{Data used}

To parameterize and evaluate the model, in major areas in terms of soybean cultivation, data of various studies on soybean (treatments without any growth and development limiting factors or environmental stresses) was applied (Tab. 1). About 35\% of published paper was applied to parameterize the model (include 34 situations for days to maturity and 26 situations for yield) and about $65 \%$ other was utilized to evaluate it (include 49 situations for yield). Parameterization of SSM iCrop2 is straightforward as presented in Appendix I of Soltani and Sinclair (2012).
Briefly, the model is tested using different values for a specific parameter, then values are chosen that provide the closest match to the observations of the major outputs, frequently final yield. Also, several model parameters that are fixed within different soybean cultivars (such as cardinal temperature) were obtained from credible references.

\subsection{Crop model}

The model used in this study was SSM iCrop2 ${ }^{1}$ (Soltani and Sinclair, 2012; Soltani et al., 2020a). The model includes daily phenology progress, leaf area development and senescence, dry matter production, yield formation, and soil water balance. Responses of crop processes to solar radiation, temperature, water availability, and cultivar differences are included in the model. Soil water sub-model accounts for soil water additions from precipitation or irrigation, and increasing rooting depth and water removal via deep drainage, run-off, soil evaporation, and plant transpiration. The soil profile is divided into two layers: one top layer of $15-20 \mathrm{~cm}$ thickness and a second layer that includes the first layer and its depth increases by root growth. Soil water balance of both layers is calculated separately. The effect of water deficit and excess on leaf area development and senescence, dry mass accumulation, and phenological development are simulated. The model also accounts for the effect of freezing temperatures on plant leaf area that might take place in early spring sowings or winter sowings. The model has been tested extensively for a wide range of plant species and proved to be robust (Soltani et al., 2020a).

Some of the parameters required in the SSM iCrop2 model for soybean are presented in Table 2.

\subsubsection{Weather data}

Meteorological information of each experimental site including minimum and maximum daily temperature, daily precipitation, and solar radiation were obtained from the nearest meteorological station. Outliers and missing data were then estimated and restored using the WeatherMan program (Hoogenboom et al., 2004).

\subsubsection{Soil data}

The required soil information included soil albedo index, Drainage coefficient, soil water volume in the field capacity, wilting point and saturation conditions. There is no local digitized soil database for crop modeling in Iran, so the HC27 database (Koo and Dimes, 2013) was utilized. The resolution of the soil database is also important. HC27 soil database used in the current study has a resolution of $10-\mathrm{km}$ which may seem coarse. Tests using SSM_iCrop2 for crop and horticultural species indicated that using HC27 soil profiles compared to actual, measured soil profiles resulted in similar output for yield and the net amount of irrigation water requirements or evapotranspiration with no significant difference with respect to mean, variance and distribution (Nehbandani et al., 2020b).

\footnotetext{
${ }^{1}$ This model can be downloaded from: "https://sites.google.com/site/ cropmodeling/-5-SSM_iCrop2".
} 
Table 1. Experiments used for parameterization and evaluation of SSM_iCrop2.

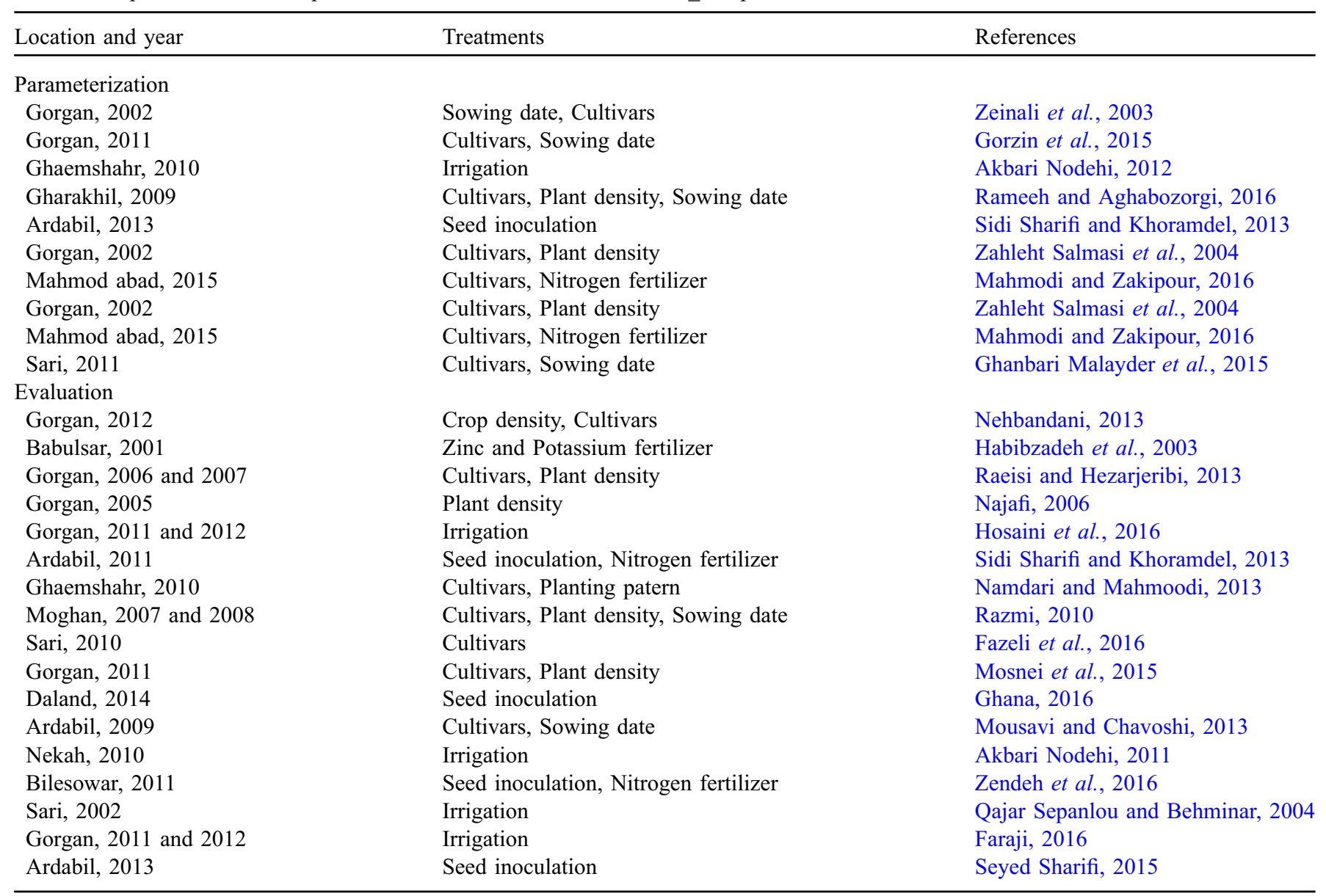

Table 2. Required weather, soil and crop management input to run SSM_iCrop2.

\begin{tabular}{|c|c|c|}
\hline Input data & Abv & Unit \\
\hline \multicolumn{3}{|l|}{ Weather data } \\
\hline Maximum daily temperature & TMAX & ${ }^{\circ} \mathrm{C}$ \\
\hline Solar radiation & SRAD & $\mathrm{MJ} \mathrm{m} \mathrm{m}^{-2} \mathrm{~d}^{-1}$ \\
\hline Daily rainfall & RAIN & $\mathrm{mm}$ \\
\hline \multicolumn{3}{|l|}{ Soil data } \\
\hline Volumetric soil water content at drained upper limit & IDUL & $\mathrm{mm} \mathrm{mm}^{-1}$ \\
\hline Volumetric soil water content at crop lower limit & ILL & $\mathrm{mm} \mathrm{mm} \mathrm{m}^{-1}$ \\
\hline Volumetric soil water content at saturation & ISAT & $\mathrm{mm} \mathrm{mm}^{-1}$ \\
\hline Curve number & $\mathrm{CN}$ & - \\
\hline Soil depth & SOLDEP & $\mathrm{mm}$ \\
\hline
\end{tabular}




\subsubsection{Crop management data}

The required crop management information included sowing date, soil moisture content during simulation, irrigation level. This data was obtained from the articles in Table 1 .

In this model, GDD was applied to determine the difference between soybean maturity groups. For this purpose, the phenological data of maturity groups 3 and 5 (major maturity groups that are grown in Iran) were used (Tab. 1). The GDD was calculated (based on soybean cardinal temperatures) for each phenological step.

\subsection{Model evaluation}

The statistical indices used for model evaluation were the coefficient of variation (CV), root mean square error (RMSE) and correlation coefficient (r). Also, the 1:1 line with $20 \%$ discrepancy was used to show the amount of deviation of the simulated versus the observed values. These statistical indices were calculated as follows:

$$
\begin{gathered}
R M S E=\sqrt{\frac{1}{n} \sum_{i=1}^{n}\left(y_{i}-x_{i}\right)^{2}}, \\
C V=\frac{\sqrt{n \sum\left(x_{i}-\bar{x}\right)^{2}}}{\sum x_{i}}, \\
r=\frac{\sum_{i=1}^{n}\left(x_{i}-\bar{x}\right)\left(y_{i}-\bar{y}\right)}{\sqrt{\sum_{i=1}^{n}\left(x_{i}-\bar{x}\right)^{2}} \sqrt{\sum_{i=1}^{n}\left(y_{i}-\bar{y}\right)^{2}}},
\end{gathered}
$$

where $x_{i}$ is the observed values, $y_{i}$ is the simulated values, $\mathrm{n}$ is the number of observations, $\bar{x}$ is the mean observed values including days to maturity or grain yield in the independent experiments, and $\bar{y}$ is the mean simulated values including days to maturity or grain yield.

\subsection{Sensitivity analysis}

Sensitivity analysis is the study of how the different input variations of a mathematical model influence the variability of its output (Monod et al., 2006). In this research, we used local sensitivity analysis, which evaluates the local impact of the variation in the input factors on a model response, focusing on sensitivity in vicinity of a set of factor values. The evaluation is conducted through gradients or partial derivatives of the output functions at these factor values, while the values of other input factors are kept constant.

To get full coverage of parameter value space and considering that the runtime for one execution of the SSM iCrop2 model is very short, we set the parameters for the different variation ranges, separately. In the model, about $10 \%$ of the crop parameters are approved to be varied with cultivar and environment (Bouman and van Laar, 2006; Tan et al., 2017). In previous studies, Tan et al. (2017) selected 16 parameters for uncertainty and sensitivity analysis, while
Sexton et al. (2017) selected 14 parameters for this purpose. In this study, 7 parameters were used for sensitivity analysis (including tuHAR, LAIMX, KPAR, IRUE, TEC, Himax and HImin). Variation range set at $\pm 30 \%$ perturbation of the default parameter values. The selection of perturbation range $( \pm 30 \%)$ was based on Tan et al. (2017) and Noorhosseini et al. (2018). For sensitivity analysis, grain yield (t.ha ${ }^{-1}$ ) and WTOP (accumulated above-ground dry matter, t.ha ${ }^{-1}$ ) were extracted as model outputs. Box plot (created with SAS software) was used to show changes in grain yield and WTOP under different parameter variation ranges. For create box plots, SAS 9.4 was used.

\section{Results and discussion}

\subsection{SSM_iCrop2 model parameterization}

To parameterize the SSM_iCrop2 model, common soybean cultivars in Iran (groups 3 and 5 ) were considered. All the parameters indicated in Table 3 were necessary for estimating soybean growth and production. Based on these parameters, SSM iCrop2 model could simulate the yield and days to maturity. The results showed that the soybean observed yields varied between 1.9 and 4.7 with an average of 3.5 tha $^{-1}$ and the range of simulated yield changes between 1.8 and 4.4 with an average of $3.9 \mathrm{tha}^{-1}$. The root mean square error (RMSE) was 0.48 tha $^{-1}$ which is equivalent to $14 \%$ of both the mean of simulated and observed yields, and the correlation coefficient (r) was 0.63 (Fig. 1). The coefficient of variation in field experiments is usually between 20 to $30 \%$ (Dadrasi and Torabi, 2016). All data were within the range of $\pm 20 \%$ of grain yield which indicates the accurate estimation of the model parameters. Regarding the phenological feature of days to maturity, the model had a good estimation so that the observed time intervals ranged from 104 to 154 days with an average of 127 days and the simulated time intervals ranged between 108 and 147 days with an average of 127 days (Fig. 2). For this feature, RMSE, the coefficient of variation (CV) and $\mathrm{r}$ were 12 days, $9 \%$ and 0.60 , respectively. Therefore, the results of parametrization based on days to maturity are considered optimal at the country level.

\subsection{Model evaluation}

To evaluate the model, the values of simulated yield was compared to the observed values. For this purpose, a set of experimental data was used (Tab. 1). For simulation, required inputs for the model and the weather data of the areas in the studied years were provided as a file to the model. The values that were estimated in the parameterization section (Tab. 3) were applied as parameters. The results showed that the model had a very good prediction of the average yield. The evaluation results of yield showed that the observed yield ranged between 1.9 to $4.8 \mathrm{t}^{\mathrm{h} \mathrm{ha}^{-1}}$ with an average of $3.5 \mathrm{t}^{-h^{-1}}$ and simulated yield changes between 1.8 to $4.5 \mathrm{tha}^{-1}$ and with an average of 3.7 t.ha $^{-1}$. Also, RMSE, $\mathrm{r}$ and CV were $0.46 \mathrm{tha}^{-1}, 0.84$ and $13 \%$ (Fig. 3), which indicated a high accuracy in the soybean yield estimation in considered provinces. Therefore, this model can be applied for different purposes. 
Table 3. SSM_iCrop2 parameter estimates for soybean in Iran.

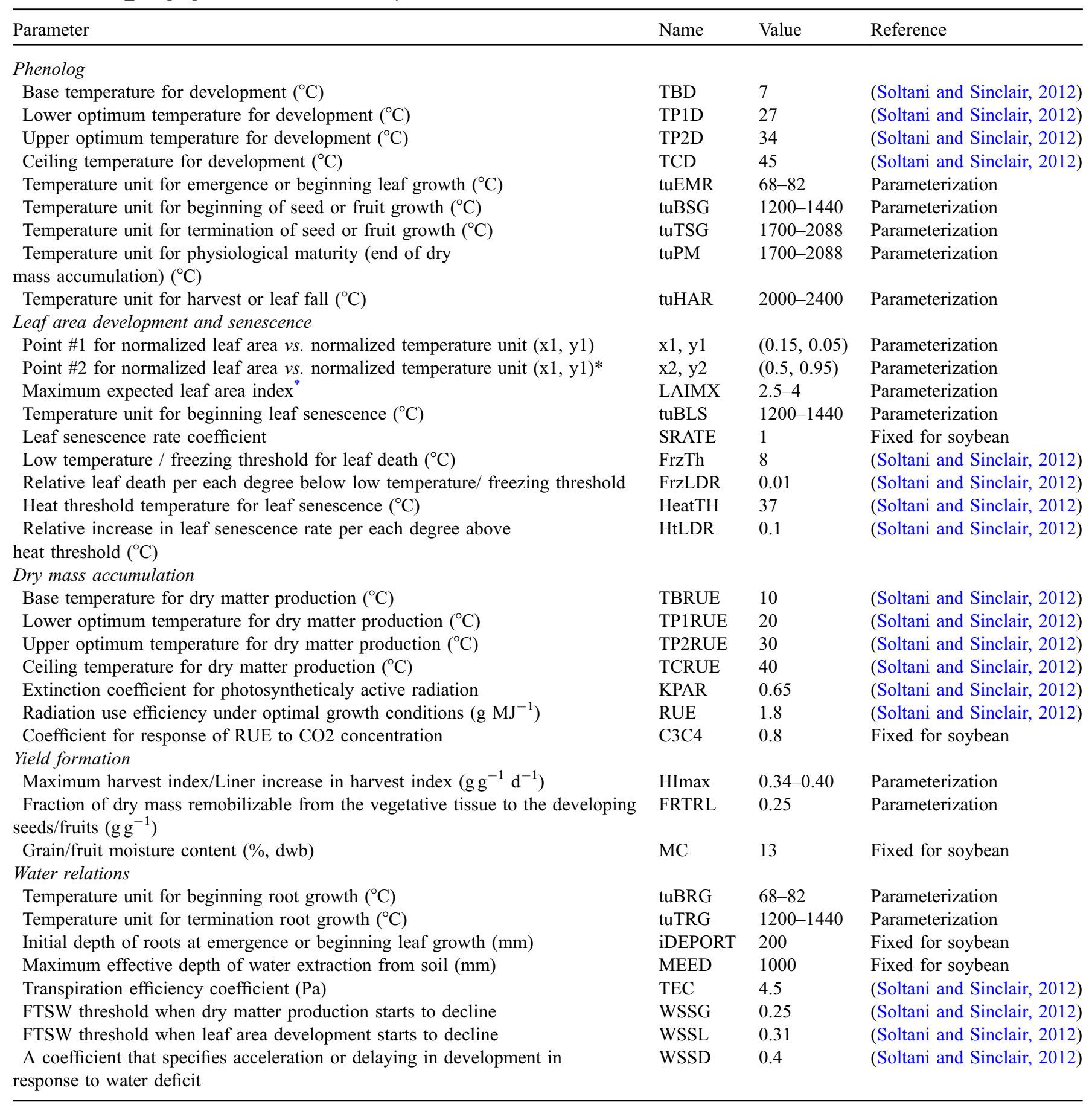

\footnotetext{
${ }^{*}$ Used as maximum plant leaf area under optimal condition (PLAMX) product by plant density.
}

\subsection{Sensitivity analysis of model parameters}

The comparison of the averages presented in Figures 4 and 5 showed that the change in the values of the tuHAR, LAIMX and KPAR parameters in the SSM iCrop2 model caused a difference in the total dry matter predicted by the model (Figs. 4 and 5). Among these parameters, the change in the amount of KPAR caused a difference in the amount of simulated dry matter, increasing and decreasing the amount of KPAR by $30 \%$ changed the total dry matter from 11.1 tha $^{-1}$ (constant and unchanged parameter) to 14.4 (increase in KPAR value) and 7.8 t.ha $^{-1}$ (decrease in KPAR value). Also, in terms of grain yield (considering $13 \%$ moisture content at the harvest time), changes in the values of tuHAR, LAIMX, KPAR and 


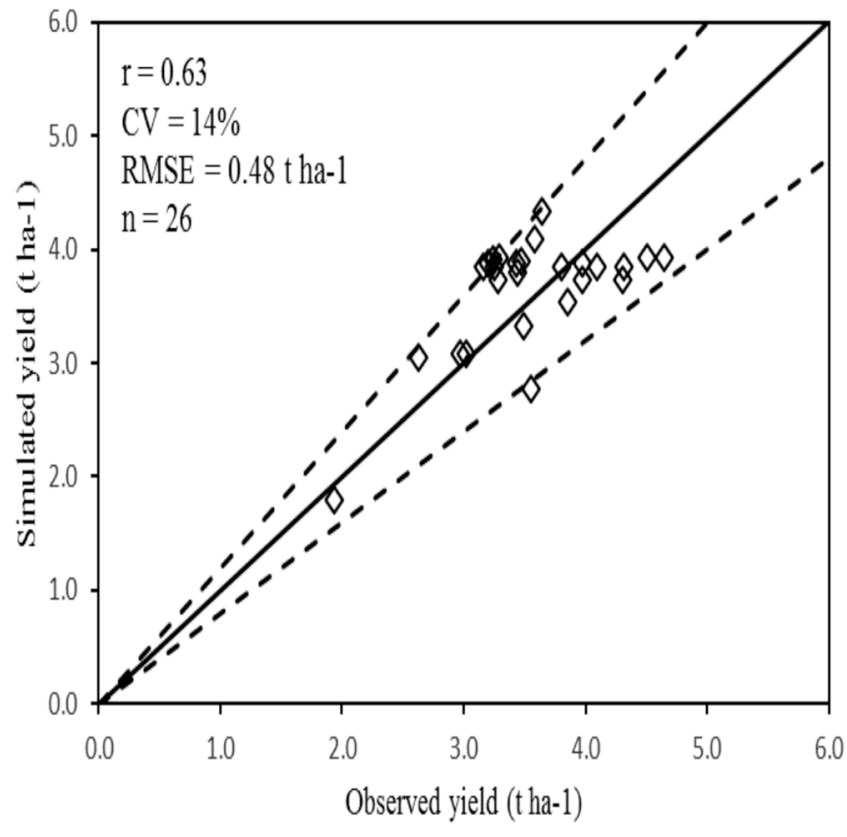

Fig. 1. Simulated versus measured dry soybean yield by SSM_iCrop2 model based on data used in model parameterization. The $\pm 20 \%$ discrepancy lines are indicated by dashed lines. Solid line is 1:1 line.

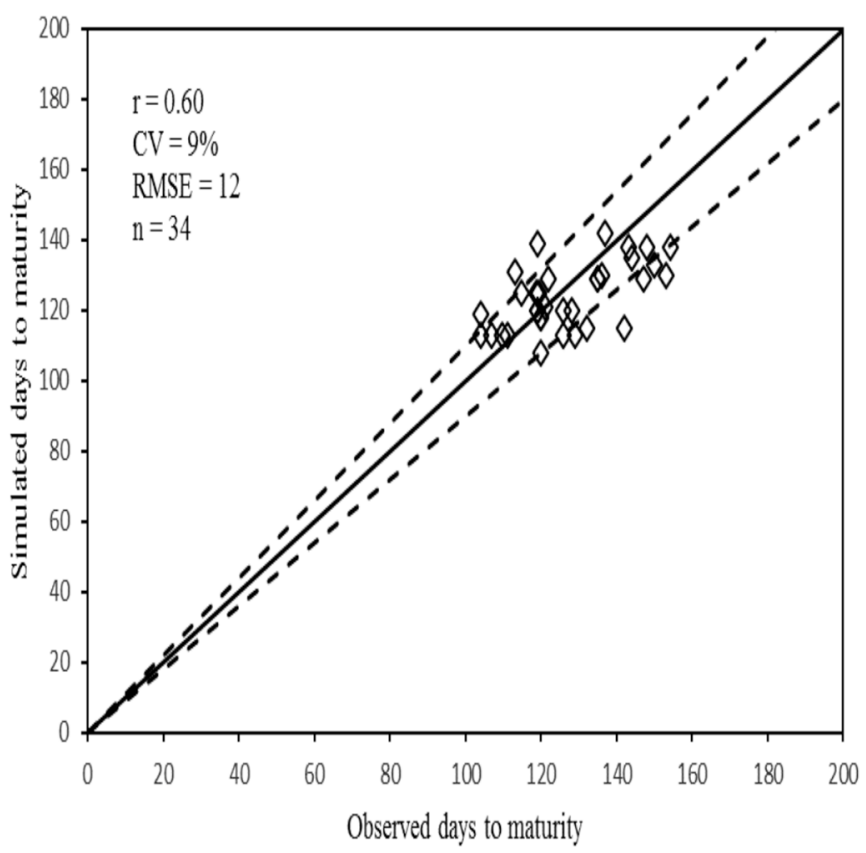

Fig. 2. Simulated versus measured days to maturity by SSM_iCrop2 model based on data used in model parameterization. The $\pm 20 \%$ discrepancy lines are indicated by dashed lines. Solid line is $1: 1$ line.

HImax parameters caused differences in predicted yield by model. Among these parameters, KPAR and HImax caused the highest difference in the predicted total dry matter. Analysis of the KPAR parameter showed that by increasing and decreasing KPAR about $30 \%$, the grain yield varied from 4.6 t.ha $^{-1}$ (constant and unchanged parameter) to 6.0 (increase in KPAR

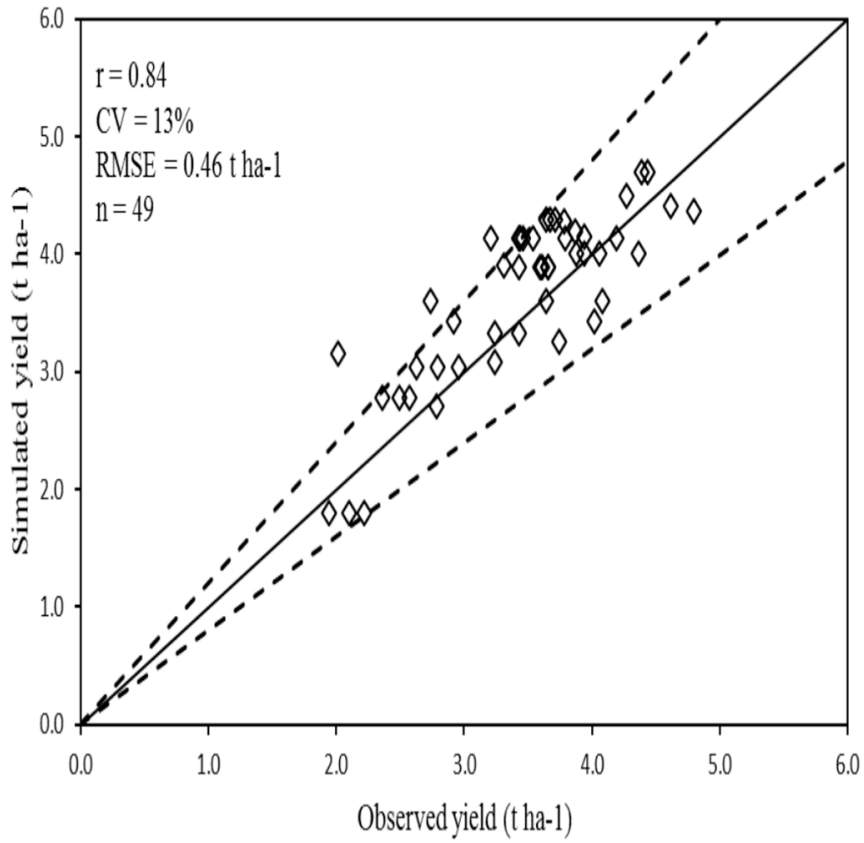

Fig. 3. Simulated versus measured dry soybean yield by SSM_iCrop2 model based on data used in model evaluation. The $\pm 20 \%$ discrepancy lines are indicated by dashed lines. Solid line is 1:1 line.

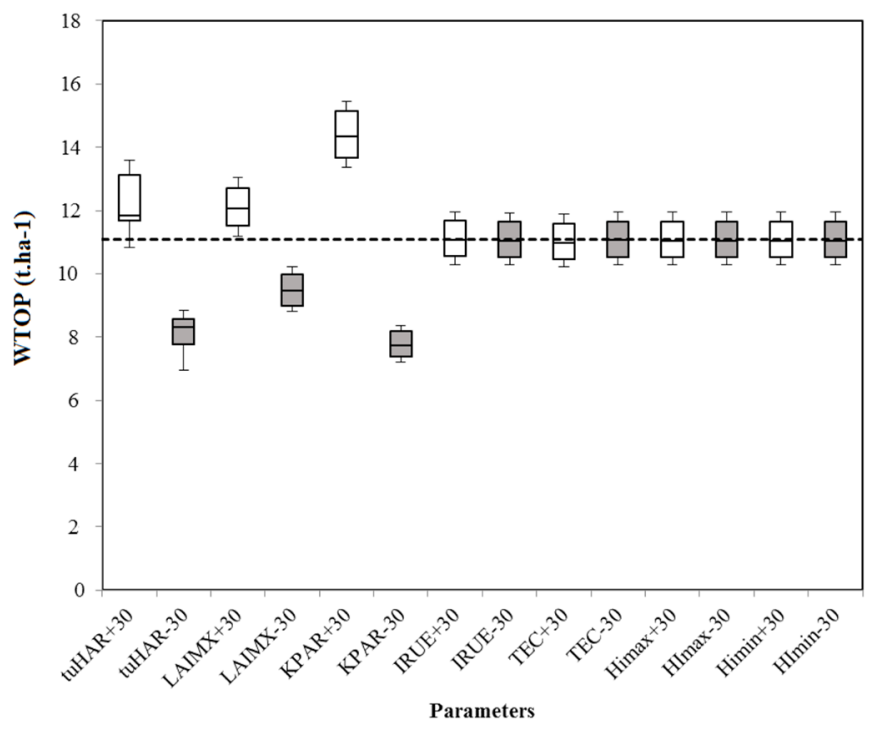

Fig. 4. The ranking of influential cultivar-specific parameters for WTOP (Accumulated above-ground dry matter, $\mathrm{t} \mathrm{ha}^{-1}$ ) under different parameter variation ranges included $+30 \%$ (White), $-30 \%$ (Grey) and Standard (Dotted line).

value) and 3.2 t.ha $^{-1}$ (decrease in the amount of KPAR). Also, Increasing and decreasing the HImax parameter value by $30 \%$ changed the grain yield from $4.6 \mathrm{t}_{\mathrm{ha}} \mathrm{ha}^{-1}$ to 6.0 and $3.2 \mathrm{t}^{\mathrm{h} \mathrm{h}^{-1}}$, respectively. The most sensitive parameters for the total dry matter were tuHAR, LAImax, and KPAR. The increase and decrease of $30 \%$ in the values of these three parameters changed the total dry matter. In terms of grain yield sensitivity to the change of parameters, different results were achieved, 


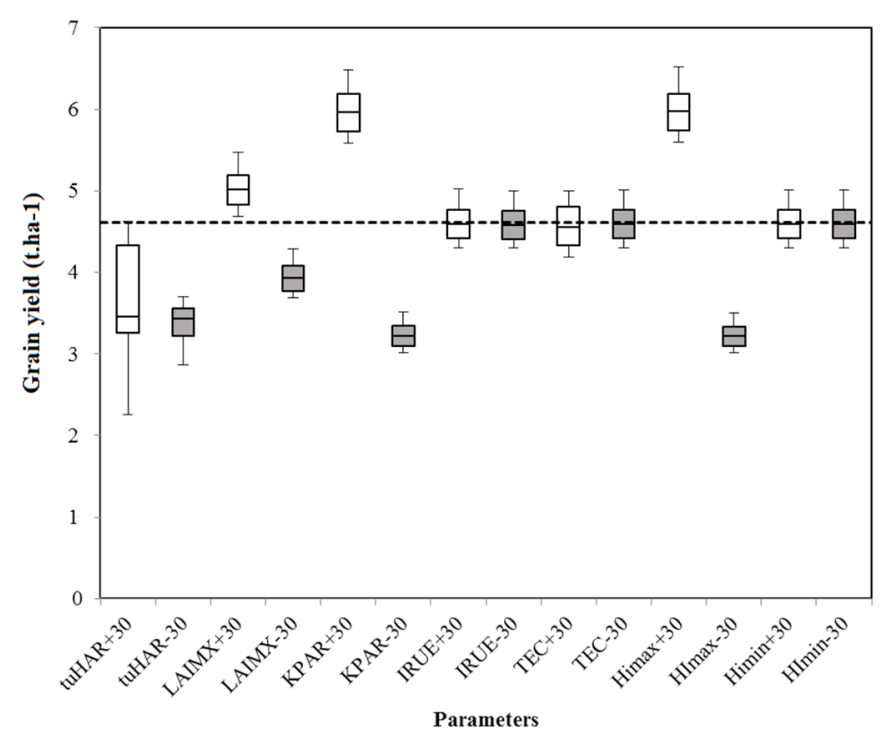

Fig. 5. The ranking of influential cultivar-specific parameters for grain yield $\left(\mathrm{t} . \mathrm{ha}^{-1}\right)$ under different parameter variation ranges included $+30 \%$ (White), $-30 \%$ (Grey) and Standard (Dotted line).

so that, in addition to the parameters affecting the dry matter, increasing and decreasing the total amount of HImax by $30 \%$ caused the most significant difference on grain yield simulated by the model. An interesting point about the grain yield was the effect of the $30 \%$ change in the tuHAR parameter, which appears to be due to the increase and decrease in the growth period of the soybean. By $30 \%$ increase in the amount of tuHAR, the vegetative growth period was increased and reproductive stage (seed filling) starts in the undesirable temperatures so yield decreased. A $30 \%$ decrease in the tuHAR amount resulted in yield reduction due to the decrease in the vegetation and reproductive growth periods which causes less dry matter transfer to the seed.

Our results indicated the SSM_iCrop2 model simulates growth and yield with reasonable accuracy across a wide range of environments in the Iran. For example, in the validation data set, observed grain yields ranged from 1.9 to $4.8 \mathrm{t} \mathrm{ha}^{-1}$, sowing dates were as April 8 to July 31, and cultivars differed in maturity from MG 3 and MG 5. SSM iCrop2 achieves this robust simulation capability with only $\overline{9}$ parameters variable.

SSM iCrop2 model has considerable advantages compared with other models. Although SSM_iCrop2 requires a maximum of 37 parameters, the actual relevant number of parameters is about half of the total number (i.e., between 15 and 20 depending on plant species) because many parameters are interconnected and some parameters are not important for some species (Soltani et al., 2020a). Whereas, the APSIM and DSSAT models needed 292 and 211 parameters to estimate the potential yield and phenological stages, respectively. (Noorhosseini et al., 2018). Due to the number of required parameters, the SSM_iCrop2 model can simulate the phenological stages of growth in a large area such as a country.

It is worth noting that, in the model can easily use an Excel spreadsheet to provide input and produce output, and also it is open source.

The studies that have been done using SSM_iCrop2 model include the following:
Soltani et al. (2020b) estimated total plant production at province and country levels by SSM _iCrop2 and a bottom-up scaling protocol (GYGA). They provided a framework within which assessing the possibility of increasing national plant production via intensification, optimizing water allocation across plant species at province and country levels by changing the cropping pattern, and assessing and prioritizing possible ways of adapting a country's agriculture to limited land and water resources and climate change. Alizadeh Dehkordi et al. (2020) evaluated potential yield of wheat by using the SSM_iCrop2 model in the Northwest of Iran. Nehbandani et al. (2020a) estimated soybean potential yield, amount of net irrigation water, evapotranspiration, vapour-pressure deficit, and soybean water productivity using the SSM iCrop2 model in Iran. Also, they investigated relationships between potential yield and environmental factors (accumulated solar radiation, rainfall, maximum temperature, and minimum temperature during the soybean growing season).

\section{Conclusion}

Crop models are essential in undertaking large scale estimation of crop production of diverse crop species, especially in assessing food availability and climate change impacts. In this research, crop simulation model (SSM_iCrop2) parameters were estimated and evaluated. The model requires limited, readily available input information. The simulations account for plant phenology, leaf area development and senescence, dry matter accumulation, yield formation, and soil water balance in a daily time step. Parameterization of this model is easy and straightforward. The results of this study showed that the SSM_iCrop2 model provides reasonable prediction of development stages and yield for the soybean in Iran. The sensitivity analysis of the parameter values showed that the most effective parameter on the total dry matter and grain yield are KPAR and HImax, respectively. This model can help find the best management plans to achieve the potential yield for different regions of the country.

Acknowledgements. This research was supported by the Agricultural Research, Training and Promotion Organization of country, which we announce our gratitude of them.

\section{References}

Akbari Nodehi D. 2011. Evaluating soybean response to water stress at different growth stages in Mazandaran province. Water Soil Res Cons $J$ 1: 53-62.

Akbari Nodehi D. 2012. Effect of drought stress in different growth stages on soybean yield and water use efficiency in Mazandaran. $J$ Sustain Agric Prod Sci 22(1): 13-23.

Alizadeh Dehkordi P, Nehbandani A, Hassanpour-Bourkheili S, Kamkar B. 2020. Yield gap analysis using remote sensing and modelling approaches: Wheat in the northwest of Iran. IJPP 1-10.

Boote KJ, Jones JW, Hoogenboom G. 1998. Simulation of crop growth: CROPGRO Model.

Bouman M, van Laar HH. 2006. Description and evaluation of the rice growth model ORYZA2000 under nitrogen-limited conditions. Agric Syst 87: 249-273.

Dadrasi A, Torabi B. 2016. Predict the growth and yield of corn in Hamedan. Iran J Field Crop Sci 47: 595-610. 
FAOSTAT. 2013. Data. [WWW Document], n.d. URL http://www. fao.org/faostat/en/\#data/TP (Accessed 6/29/20).

Faraji A. 2016. Evaluation of soybean new genotypes in terms of drought tolerance indices. Reprod Crops 8(18): 30-36.

Fazeli F, Najafi Zarini H, Arefrard M, Mirabadi A. 2016. Assessment of relation of morphological traits with seed yield and their diversity in M4 generation of soybean mutant lines [Glycine max (L.) Merrill] through factor analysis. J Crop Breed 7: 47-55.

Ghana P. 2016. Evaluation the effect of phosphorus solubilizing bacteria, inoculation of rhizobium and zinc solubility on soybean yield and yield components of Katoul cultivar in Golestan. J Oil Plants Prod 3(1): 25-35.

Ghanbari Malayder A, Janbaz Ghobadi Gh, Dastan S, Shahidifar A. 2015. Evaluation of changes in the length of day and growth phenology of soybean cultivars in different planting dates in Sari. Agric Res 7(1): 41-53.

Geerts S, Raes D. 2009. Deficit irrigation as an on-farm strategy to maximize crop water productivity in dry areas. Agric Water Manag 96: 1275-1284.

Gorzin M, GhaderiFar F, Zainali E, Razavi SE. 2015. Effect of the length of various developmental periods on soybean yield and yield components. Elec J Crop Prod 8(1): 21-41.

Habibzadeh F, Amini A, Miernia Kh. 2003. Evaluation the effect of different potassium value and zinc on the yield and yield components of soybean in Mazandaran province. J Pazhu Saz 60: $18-24$.

Hoogenboom G, Jones JW, Wilkens PW, et al. 2004. Decision support system for agrotechnology transfer version 4.0. Honolulu, HI: Univ. Hawaii.

Hosaini T, Khoshravesh M, Ziatabar Ahmadi M, Ghadami Firozabadi A. 2016. Evaluation soybean yield using AquaCrop model under salinity and water difinency management. $J$ Water Res Agric 30 (3): 361-372.

Hsiao TC, Heng L, Steduto P, Rojas-Lara B, Raes D, Fereres E. 2009. AquaCrop - The FAO crop model to simulate yield response to water: III. Parameterization and testing for maize. Agron J 101: 448-459.

Keating BA, Carberry PS, Hammer GL, et al. 2003. An overview of APSIM, a model designed for farming systems simulation. Eur $J$ Agron 18: 267-288.

Koo J, Dimes J. 2013. HC27 Generic Soil Profile Database. Harvard Dataverse Ver. 4.

Mahmodi M, Zakipour V. 2016. The effect of nitrogen on yield and yield components of soybean in the city of Mahmudabad. Agron Res Edge Desert 13(1): 73-81.

Ministry of Agriculture Jihad. 2016. Agricultural Statistics. [WWW Document], n.d. URL https://www.maj.ir/ (Accessed 6/29/20).

Monod H, Naud C, Makowski D. Uncertainty and sensitivity analysis for crop models. In: Wallach D, Makowski D, Jones JW, eds. Working with dynamic crop models: Evaluation, analysis, parameterization, and applications. Amsterdam (The Netherlands): Elsevier, 2006.

Mosnei H, Ajmnorouzi H, Rangriz Z, Zarez Zadeh Z. 2015. The effect of planting pattern on phenological stages, yield and yield components of soybeans promising in Gorgan. Plant Physio 7 (20): 43-58.

Mousavi S, Chavoshi S. 2013. Evaluation of phenological traits and some important cultivars of soybean cultivars under different planting dates in Ardabil. Iran J Agric Sci 7(4): 371-382.

Najafi R. 2006. Effect of seed power on soybean growth and yield. Master's Thesis group Agriculture, Faculty of Plant Production, Gorgan University of Agricultural Sciences and Natural Resources.
Namdari M, Mahmoodi S. 2013. Evaluation of grain yield and yield components in intercropping of dwarf and tall cultivars of soybean (Glycine max L.). Iran J Crop Sci 15(1): 1-11.

Nehbandani A. 2013. Parameterization of SSM model for soybean growth and yield. Master's Thesis group Agriculture, Faculty of Plant Production, Gorgan University of Agricultural Sciences and Natural Resources.

Nehbandani A, Soltani A, Rahemi Karizaki A, Dadrasid A, Nourbakhsh F. 2020a. Determination of soybean yield gap and potential production in Iran using modelling approach and GIS. JIA 19: 2-14.

Nehbandani A, Soltani A, Taghdisi Naghab R, et al. 2020b. Assessing HC27 Soil Database for Modeling Plant Production. Int J Plant Prod accepted.

Noorhosseini SA, Soltani A, Ajamnoroozi H. 2018. Simulating peanut (Arachis hypogaea L.) growth and yield with the use of the Simple Simulation Model (SSM). Comput Electron Agric 145: 63-75.

Qajar Sepanlou M, Behminar MA. 2004. Irrigation effect in different stages of growth on yield, water use efficiency and harvest index of soybean cultivars in Mazandaran. Agric Nat Res Caspian Sea 2 (2): 79-88.

Raeisi S, Hezarjeribi A. 2013. Evaluation of soybean cultivars in different planting arrangements and densities in Golestan Province of Iran. Seed Plant Prod J 29(2): 215-233.

Rameeh V, Aghabozorgi M. 2016. Effect of different seed rates and sowing dates on yield components, yield and qualitative traits of soybean (Glycine max (L.) Merr.) variety Sari. J Oil Plants Prod 3 (1): 15-24.

Razmi N. 2010. Effect of sowing date and plant density on some agronomic characteristics, grain yield and its components in soybean genotypes in Moghan region. Seed Plant Prod J 26(4): 403-418.

Setiyono TD, Cassman KG, Specht JE, et al. 2010. Simulation of soybean growth and yield in near-optimal growth conditions. Field Crop Res 119: 161-174.

Sexton J, Everingham L, Inman-Bambera G. 2017. A global sensitivity analysis of cultivar trait parameters in a sugarcane growth model for contrasting production environments in Queensland, Australia. Eur J Agron 88: 96-105.

Seyed Sharifi R. 2015. The Effect of Zinc Application and Biological Fertilizers on Seed, Function and Some Soybean Growth Characteristics. Agric Prod 17(1): 109-130.

Sidi Sharifi A, Khoramdel S. 2013. Effects of nano-zinc oxide and seed inoculation by plant growth promoting rhizobacteria (pgpr) on yield, yield components and grain filling period of soybean (Glycine max 1.). IRN J Field Crop Res 13: 738-753.

Sinclair TR, Muchow RC. 1999. Radiation use efficiency. In: Advances in Agronomy. Elsevier, pp. 215-265.

Soltani A. 2009. Mathematical modeling of the crop. Publication Mashhad University Jihad, $175 \mathrm{p}$.

Soltani A. 2012. Modeling physiology of crop development, growth and yield. CABi.

Soltani A, Sinclair TR. 2012. Identifying plant traits to increase chickpea yield in water-limited environments. Field Crop Res 133:186-196.

Soltani A, Alimagham SM, Nehbandani A, et al. 2020a. SSM_iCrop2: A simple model for diverse crop species over large areas. Agric Syst 182: 102855.

Soltani A, Alimagham M, Nehbandani A, et al. 2020b. Modeling plant production at country level as affected by availability and productivity of land and water. Agric Syst 183: 102859. 
Tan J, Cui Y, Luo Y. 2017. Assessment of uncertainty and sensitivity analyses for ORYZA model under different ranges of parameter variation. Eur J Agron 91: 54-62.

Torabi B, Soltani A, Galeshi S, Zeinali E. 2011. Assessment of yield gap due to nitrogen management in wheat. Aust J Crop Sci 5: 879 .

Williams SL, Watson N. 1985. Perceived danger and perceived selfefficacy as cognitive determinants of acrophobic behavior. Behav Ther 16: 136-146.

Zahleht Salmasi S, Mehaghani R, Ghasemi Golazani K, Alari H, Raeisi S. 2004 Yield evaluation, speed and durability of seed filling of three soybean varieties in different densities. Agric Sci 1 (4): 141-152.

Zeinali E, Ghadirifar F, Soltani A, Kashiri H. 2003. Effect of planting date on yield and yield components of three soybean cultivars in Gorgan. Iran Crop Res 1: 81-92.

Zendeh A, Ansari MH, Khorshidi MB. 2016. Effect of nitrogen fertilizer and Pseudomonas putida inoculation on yield and yield component of soybean as second crop in Moghan region. Agron $J$ 12(2): $35-42$.

Cite this article as: Nehbandani A, Soltani A, Nourbakhsh F, Dadrasi A. 2020. Estimating crop model parameters for simulating soybean production in Iran conditions. OCL 27: 58 